\title{
Reflexões sobre comunicação organizacional na América Latina: ventos da mudança na gestão da diversidade
}

Reflections on organizational communication from Latin America: the winds of change in diversity management

Reflexiones sobre la comunicación organizacional desde América Latina: vientos de cambio en la gestión de la diversidad

\section{Maria Aparecida Ferrari}

- $\quad$ Professora Associada da Escola de Comunicações e Artes da Universidade de São Paulo (ECA-USP).

- $\quad$ Livre-docente em Relações Públicas pela USP.

- $\quad$ Doutora em Ciências da Comunicação pela USP, com período de estudos na Universidade de Maryland (EUA).

- Mestra em Ciências da Comunicação pela USP.

- $\quad$ Graduada em Ciências Sociais pela ỦSP e em Relações Públicas pela Universidade Anhembi Morumbi.

- E-mail: maferrar@usp.br 


\section{Resumo}

Este artigo destaca a legitimação dos modelos de gestão eurocêntricos nas organizações latino-americanas e sua influência na cultura e nos processos de comunicação. Observa-se que ainda estão presentes matrizes eurocêntricas que deram origem a profundos paradoxos e contradições na agenda das organizações e limitaram o desenvolvimento de uma identidade latina. Esse cenário tem dificultado a gestão da diversidade nas organizações latino-americanas, uma vez que traços como o machismo e o autoritarismo impedem um espaço de resistência e inclusão social.

\section{PALAVRAS-CHAVE: COMUNICAÇÃO ORGANIZACIONAL・ESTUDOS CULTURAIS • CULTURA ORGANIZACIONAL・GESTÃO DA DIVERSIDADE • DIVERSIDADE CULTURAL.}

\section{Abstract}

This article highlights the legitimacy of euro-centric management models in Latin American organizations and their influence on culture and communication processes. The prevalence of euro-centric schemes has resulted in profound paradoxes and contradictions in organizational agendas and have constrained the development of a truly Latin American identity. This scenario has hampered diversity management in Latin American organizations due to the authoritarianism and male dominance traits that have limited the space for resistance and social integration.

KEYWORDS: ORGANIZATIONAL COMMUNICATION • CULTURAL STUDIES • ORGANIZATIONAL CULTURE • DIVERSITY MANAGEMENT • CULTURAL DIVERSITY.

\section{Resumen}

Este artículo destaca la legitimidad de los modelos eurocéntricos de gestión en organizaciones latinoamericanas y su influencia cultural y en los procesos de comunicación. Aún se encuentran matrices eurocéntricas que dieron lugar a profundas paradojas y contradicciones en la agenda de las organizaciones y limitaron el desarrollo de una identidad latina. Este escenario dificulta la gestión de la diversidad en las organizaciones latinoamericanas, ya que rasgos como el machismo y el autoritarismo impiden un espacio de resistencia e inclusión social. 


\section{INTRODUÇÃO}

$\mathrm{P}$ ensar a comunicação organizacional na região latino-americana exige voltar o olhar para os estudos culturais, com vistas a identificar as bases que edificaram as culturas nacional e organizacional nos países e organizações da região. A relação entre cultura e comunicação é uma "marca distintiva" (Rizo, 2020) que tem caracterizado os estudos de comunicação na região desde os anos 1980, pela influência dos estudos culturais da Escola de Birmingham, com Stuart Hall e Richard Hoggart e, mais tarde, pelas propostas de Jesús Martín-Barbero e Néstor García Canclini, considerados os principais exponentes dos estudos culturais na América Latina.

Este artigo busca sublinhar que a cultura e a comunicação são fenômenos inter-relacionados e que não podem ser compreendidos separadamente. Essa relação exige, acima de tudo, que se considere a comunicação como um processo fundamental para a construção da vida em sociedade, além de um mecanismo ativador de diálogo e convivência entre sujeitos sociais, e a cultura, como um sistema de significados aceito pública e coletivamente por dado grupo durante certo tempo (Pettigrew, 1979).

As reflexões propostas partem do pressuposto de uma América Latina entendida como uma construção discursiva, aparentemente subalterna em relação à Europa, associada à dificuldade de produção independente de conhecimentos originários dos países do hemisfério Norte, apesar de muito do conhecimento europeu ter sido adaptado nos países latino-americanos (Szlechter et al., 2020), o que dificultou uma epistemologia da descolonização (Mignolo, 2011).

A análise desse contexto exige que se compreenda o advento e o desenvolvimento de teorias dos estudos organizacionais para, em seguida, compreender o pensamento comunicacional latino-americano, visto que o conhecimento importado sempre prevaleceu e foi valorizado acima das ideias locais.

Este texto reflete, ainda que brevemente, sobre alguns aspectos da cultura nacional e organizacional que influenciaram os processos de comunicação nas/das organizações na América Latina, especialmente no que diz respeito à importação de modelos de desenvolvimento alheios e desajustados à realidade dos países da região.

Mediante o entendimento de especificidades e particularidades de emergência e desenvolvimento de teorias dos estudos culturais e organizacionais, propõe-se contextualizar o pensamento comunicacional latino-americano e identificar as dificuldades de produção de um pensamento próprio, uma vez que o conhecimento importado sempre predominou na região. 0 propósito do artigo é, assim, contribuir para a construção de uma agenda que permita refletir sobre aspectos simbólicos e culturais da comunicação organizacional e, em especial, sobre a gestão da diversidade nas organizações latino-americanas.

0 artigo está estruturado em sete seções: a segunda trata dos aspectos políticos, econômicos e culturais da América Latina; a terceira apresenta o desafio das organizações latino-americanas na mudança de gestão eurocêntrica para um modelo com características locais. Os aspectos da cultura organizacional e o que distingue as organizações da região são discutidos na quarta seção. A quinta reflete sobre a comunicação como processo de produção de sentidos, e a sexta traz o panorama da gestão da diversidade no contexto das organizações latino-americanas. A seção sete encerra o texto com as considerações finais. 


\section{AMÉRICA LATINA A PARTIR DE UMA ÓTICA POLÍTICA, ECONÔMICA E CULTURAL}

Ainda que de maneira breve, é importante destacar alguns aspectos do processo de colonização na América Latina que, ao longo dos séculos, conferiu à região uma identidade baseada em uma visão de inferioridade e de subdesenvolvimento das sociedades locais (Ferrari, 2011).

Apesar da forte influência da globalização no século XX, vale destacar que esse fenômeno global não chegou a erradicar as particularidades de cada realidade local. Ainda que a globalização tenha mostrado uma aparente supressão das diferenças, as evidências indicam que estas permaneceram e se multiplicaram. Neste sentido, Eduardo lbarra-Colado (2008) afirma com afinco que:

Na América Latina, mas também em outras regiões do planeta que sofreram e ainda sofrem o processo de colonização, há que provincializar Europa (que também significa, e, sobretudo, provincializar Estados Unidos), para reconhecer a importância do espaço geopolítico na constituição da nossa identidade e nossa forma de ser. [...] Necessitamos um pensamento original que tenha em conta os problemas organizativos da América Latina, desde o reconhecimento da história de sua conformação econômica e política e seu enorme patrimônio cultural, que operam sob outros modelos de racionalidade. (Ibarra-Colado, 2008, p.221)

Se, por um lado, a maioria dos países latino-americanos conseguiu grandes avanços para a consolidação de suas instituições democráticas no século XX, outros seguem apegados a valores do caudilhismo que marcou a história do continente desde a conquista da independência. Apesar de já contar com suas instituições consolidadas, certos países ainda não podem ser considerados como nações genuinamente democráticas, por causa do aumento persistente das desigualdades sociais.

Esta dicotomia entre inovar e preservar valores e traços culturais se traduz em uma equação difícil de resolver nos países latino-americanos, ao contrário do que ocorre nos países desenvolvidos que, historicamente, estabeleceram valores em suas sociedades que foram seguidos pelo mundo empresarial e ditaram modelos seguidos na região latino-americana.

Ferrari (2011) destaca que o desenvolvimento político e econômico do continente latino-americano não corresponde às necessidades que impõem suas dimensões geográficas, e se refere a Martín-Barbero (2006, p.22), que oferece uma interessante reflexão quando afirma que a "América Latina contém a 'resistência' de suas tradições e a contemporaneidade de seu atraso, as contradições de sua modernização e as ambiguidades de seu desenvolvimento, seu modernismo e sua tardia e heterogênea modernidade", o que, de maneira análoga, transformou o continente em um amplo "laboratório" em que se misturam culturas e civilizações, rodeadas de forças que atuam como reativos de um labirinto de experimentos, pressões e contradições socioculturais (Ferrari, 2011).

O breve cenário que se desenha serve para colocar no centro da reflexão as práticas organizacionais latino-americanas atuais, principalmente ante os efeitos do fenômeno da globalização. Em um texto publicado originalmente em 1972, no contexto da celebração do 500 aniversário da invasão na América, Aníbal Quijano (2000, p.117) afirmou que "a globalização atual é, em primeiro lugar, a culminação de um processo que começou com a constituição da América e o capitalismo colonial/moderno e eurocêntrico como novo padrão de poder mundial". Hoje seria necessário ir além e entender que parte dessa "desobediência epistêmica" (Mignolo, 2007, p.45) seria "não poder aceitar-se, após mais de 500 anos de história comum, como não ocidentais e, muito menos permitir que exista um trato como sendo o 'outro' na própria casa" (Flores Prieto; Pozo; Crawford, 2018, p.97).

Quando buscamos a origem dos referenciais teóricos dos estudos organizacionais latino-americanos para logo entender como se dá o processo de comunicação, observamos que, durante muito tempo, as referências utilizadas foram aquelas anglo-saxãs, mediante suas teorias, métodos e referências bibliográficas, e assumindo suas próprias agendas de pesquisa como se fossem nossas (Ibarra-Colado, 2008). 
A constituição e a consolidação de uma identidade latino-americana requerem o conhecimento do próprio território, para logo se aprofundar, de maneira particular e única, na lógica em que as organizações da região se desenvolvem e sobrevivem no dia a dia. Portanto, a própria realidade do cotidiano permite identificar, compreender e analisar o traço "latino" das organizações da região (Gonzáles-Miranda, 2020), que permite iniciar uma desconstrução distante dos referenciais estrangeiros preconcebidos e realizar uma reconceituação constante do que é América Latina para o restante dos países. Ter em conta um discurso próprio, sustentado por uma análise de distintas realidades locais da América Latina, sem dúvida irá colaborar para a compreensão e o conhecimento do mundo organizacional global (Gonzáles-Miranda, 2020).

\section{DA DEPENDÊNCIA À EMANCIPAÇÃO DAS ORGANIZAÇÕES LATINO-AMERICANAS}

Diante do contexto apresentado, constata-se que, nas últimas décadas do século XX e no início do século XXI, as organizações latino-americanas incrementaram seus modelos de gestão para sobreviver em um ambiente que antes era desconhecido e que agora funciona segundo regras globais impostas para a manutenção no mercado (Ferrari, 2011).

Para as organizações latino-americanas, além da necessidade de transitar da lógica econômica para a social, o grande desafio consiste em desenvolver novas competências no complexo mundo interconectado. Esse desafio só poderá ser superado através do rompimento dos modelos conceituais do mundo anglo-saxão e da adoção de um modelo de gestão com características culturais locais.

Szlechter et al. (2020) afirmam que, diferentemente dos países do hemisfério Norte, na "América Latina o capitalismo industrial não surgiu como uma resposta endógena a rupturas políticas e econômicas de perfil liberal, mas foi importado e implantado de maneira tardia, em um contexto que precisamente não era liberal" (p.85). Tal afirmação retrata uma época em que predominavam as concepções oligárquicas que eram conduzidas por elites tradicionais. Os autores concluem que sob este capitalismo incipiente na região "as organizações que surgiram são um híbrido particular, com profundos paradoxos e contradições, muitos dos quais se opõem radicalmente às concepções racionais do liberalismo em relação à política, economia, ciência e sociedade" (p.85). Essas organizações são entendidas como fruto de uma hibridização que, na prática, mesclou religião (católica), Estado e mercado, tudo isso funcionando simultaneamente com tradições profundas de coletivismo e dependência das elites conservadoras tradicionais.

Do contexto exposto pelos autores depreende-se que, apesar do esforço em mudar os modelos de gestão, os traços da cultura nacional seguiram fortemente enraizados nas orientações burocráticas, clientelistas e personalistas. E, como comenta Ibarra-Colado (2008, p.91), "infelizmente, na América Latina, ainda não foram realizados suficientes estudos que possibilitem uma interpretação das consequências sociais da gestão e do desempenho organizacional".

A proposta de mudança dos modelos de gestão, antes baseados nos parâmetros anglo-saxões, é uma quebra de paradigma, uma vez que a tradição sempre foi buscar referências de modelos no hemisfério Norte, pois, historicamente, quem desenvolvia teorias eram os grupos com perfil eurocêntrico, em sua maioria homens brancos e não indígenas, demonstrando como as dinâmicas peculiares dos próprios contextos locais foram abandonadas (Szlechter et al., 2020).

O grande desafio para as organizações da região consiste em repensar os referenciais globais e interpretar a gestão como prática social local, incorporando diferentes finalidades de ação (Ibarra-Colado, 2006), como a gestão da sustentabilidade e da diversidade.

Um exemplo da dificuldade que as organizações latino-americanas, com seus padrões culturais não locais e visão funcionalista, têm para adaptar políticas e processos externos é a gestão da diversidade. De acordo com Alves e Galeão-Silva (2004), isso ocorre quando a gestão da diversidade é considerada uma vantagem competitiva e não é vista como um vínculo entre a empresa e seu 
contexto social; tal posicionamento explica a gênese das desigualdades estruturais instituídas nos países latino-americanos a partir da dinâmica do poder colonialista. Desta forma, como afirmam Szlechter et al. (2020, p.87), "as práticas de gestão voltadas para o combate às desigualdades de gênero, raça, classe, origem étnica e sexualidade produzem poucos resultados".

Até aqui foram destacados alguns aspectos históricos da região e a forma como as organizações passaram por um processo de hibridização, mediante a adoção de matrizes hegemônicas e as tradições coletivistas e de dependência das elites conservadoras locais.

Diante do cenário apresentado, coloca-se uma questão: quais são as dificuldades que enfrentam as organizações da região para pôr em prática uma gestão humanizada de seu capital humano e intelectual, segundo os traços culturais locais? Este artigo não tem a pretensão de responder de maneira absoluta a questão posta, dado que sua discussão sempre suscitará interpretações, uma vez que se trata de um processo em permanente revisão.

\section{ASPECTOS DA CULTURA ORGANIZACIONAL: O QUE DISTINGUE AS ORGANIZAÇÕES DA REGIÃO}

Apesar das riquezas de recursos naturais e humanos na região, ainda é incipiente o impacto dos países da América Latina na economia mundial, uma vez que graves problemas persistem, tais como a fragilidade dos sistemas políticos e econômicos, a desigualdade na distribuição de renda, 0 alto índice de analfabetismo, a miséria e a fome.

Como mencionado, são poucos os estudos sobre organizações latino-americanas e sua cultura, e essa ausência de teorias próprias é resultado da absorção excessiva de teorias e estudos vindos do hemisfério Norte (Dávila; Martínez, 1999; Prestes Motta; Caldas, 1997).

Ao considerar que a cultura organizacional é uma construção social coletiva e dinâmica, compartilhada por pessoas e grupos sociais que percebem, pensam e reagem diante de diferentes espaços, acredita-se que é por meio de seus elementos que se produzem as práticas de comunicação (Ferrari, 2011). Por sua vez, ao definir as organizações como um "fenômeno de comunicação" (Freitas, 1991, p.34), destaca-se que o processo de comunicação ocorre em um espaço de interações em que as manifestações dos indivíduos permitem a elaboração de novas perspectivas e, portanto, novos significados, que, por sua vez, constroem os elementos da cultura organizacional. Ou seja, comunicação e cultura estão inter-relacionadas, na medida em que uma é influenciada pela outra. Sendo a comunicação um elemento fundamental na construção da cultura, sem o qual ela não existiria, os meios de comunicação também estão fortemente condicionados a um contexto cultural específico (Aidar; Alves, 1997).

Essa perspectiva permite compreender: 1) que a cultura detém um papel importante na formação de valores, atitudes e comportamentos dos membros de uma organização em diferentes sociedades; 2) que os valores e atitudes culturais variam em grau de importância de uma sociedade para outra; e 3) que diferentes grupos sociais se comportam de maneira distinta em circunstâncias semelhantes, uma vez que adotam valores e atitudes inerentes à sua cultura.

Foi enfatizado que pesquisas de campo e estudos críticos locais sobre as características da cultura organizacional nas organizações latino-americanas ainda são limitadas. Por outro lado, observa-se que abundam relatórios produzidos por consultorias internacionais e nacionais que tratam a cultura das organizações como um ativo que, segundo eles, pode ser alterado de um momento para o outro, reforçando o enfoque funcionalista nesta matéria (Ferrari, 2011). É possível que essa produção de matrizes e parâmetros elaborados pelas referidas consultorias tenha procurado resolver pressões externas e internas das organizações que foram fruto das últimas décadas do século XX, em decorrência de processos 
de privatizações, fusões, aquisições, reestruturações ou de substituição de modelos de gestão. Todas essas mudanças, frutos do novo capitalismo (Sennett, 2000), aludem a uma nova ordem do sistema econômico que transformou o capitalismo industrial em capitalismo flexível, com o objetivo de reconfigurar a institucionalidade em todos os âmbitos do sistema econômico e das organizações.

Entre os estudos existentes sobre dimensões e traços do sistema cultural latino-americano nas organizações da região, podem ser mencionados os trabalhos de Fernando Prestes Motta e Miguel Pinto Caldas (1997), Enrique Ogliastri (2000)', Geert Hofstede (2001) e Betania Tanure (2005), que oferecem elementos para refletir sobre traços culturais locais e, consequentemente, sobre o processo de comunicação. Ainda que a produção dos autores possa ser interpretada como funcionalista por alguns críticos, os resultados obtidos permitem compreender como foram construídas as subjetividades dos latinos, qual é o sentido que as pessoas conferem ao trabalho e de que maneira as práticas culturais influem nos processos comunicativos.

Essa aproximação às dimensões culturais permite, assim, iniciar uma desconstrução, se possível a partir de referências estrangeiras, para posteriormente identificar elementos da cultura organizacional latino-americana e sua influência nas práticas comunicativas.

Entre as seis dimensões culturais propostas por Hofstede (2001) que foram desenvolvidas em um estudo que cobriu um período de mais de 30 anos, a dimensão "aversão à incerteza" é resultado da vulnerabilidade que afeta permanentemente os contextos político, social e econômico dos países da região. Uma vez que esse cenário leva as organizações a adotarem no nível micro um excesso de regras e normas com o objetivo de organizar, disciplinar e punir quem as descumprir e, à medida que o controle da incerteza se torna impossível, a ambiguidade passa a ser uma atitude tolerada, muitas vezes produzindo discursos cujos significados constrangem os sujeitos em suas ações.

O "distanciamento do poder" é outra dimensão cultural presente nas organizações latinas e é caracterizado pelo exercício da prática do poder em estruturas hierárquicas verticais. Os resultados são observados em ambientes de trabalho em que se fomenta a desigualdade, o poder explícito, a tradição, a centralização das decisões e o elitismo. Essas organizações geralmente são caracterizadas por autoritarismo, personalismo e paternalismo que normalmente impedem o reconhecimento e a participação dos trabalhadores, tão necessários para estimular competências como a criatividade e a flexibilidade. Nessa dimensão, o que está subjacente é a vigilância e o controle das pessoas.

A distância do poder também reforça a prática de valores masculinos como a assertividade, a busca constante por resultados tangíveis e a atuação competitiva, que impede a promoção do diálogo, reforça a gestão autoritária e dificulta a diversidade cultural. Esse cenário oferece "um dispositivo" através do qual operam os poderes disciplinar (Foucault, 1980) e "gerencial" (Gaulejac, 2007), que servem para observar, quantificar e regularizar em função dos resultados que possibilitem a permanência e a mobilidade naquele espaço hierárquico.

Desta forma, as dimensões culturais mencionadas apontam para características que se encontram presentes na região e que dificultam um olhar inclusivo, democrático e participativo que permita o exercício do respeito à diversidade.

1 Enrique Ogliastri participou do projeto Global Leadership and Organizational Behavior Effectiveness Research (Globe), coordenado por Robert House em 64 países. Nos estudos Globe foram incorporadas as dimensões culturais de Geert Hofstede (2001). Ogliastri foi responsável por analisar os dados referentes a aproximadamente 1.400 gerentes latino-americanos. 


\section{A COMUNICAÇÃO COMO PROCESSO DE PRODUÇÃO DE SENTIDOS}

O final da Segunda Guerra Mundial gerou um cenário "para as primeiras reflexões críticas comunicacionais no continente, como foi o de reconhecer que o pensamento comunicacional latino-americano nasce como antípoda da submissão de uma comunicação a favor do status quo", segundo Herrera (2015, p.127).

Ainda na primeira metade do século XX, as práticas de comunicação nas organizações latino-americanas baseavam-se no enfoque funcionalista, sob a premissa de que "comunicação é persuasão". Este paradigma clássico da comunicação como um processo de transmissão da informação foi entendido como o ato de produzir mensagens e/ou conteúdos e informar, de acordo com as estratégias estabelecidas pelas organizações. Neste sentido, a noção de comunicação tende a ser simplificada para dar conta de ideias de urgência e economia presentes nos objetivos das organizações naquele momento.

Oliveira e Paula (2007, p.23) apontaram que o paradigma clássico-informacional-funcionalista, que ainda sustentava parte dos estudos de comunicação e administração na região, era "insuficiente para administrar a abundância de fluxos, demandas informacionais e o aumento da rede de relações estabelecidas entre a organização e os atores sociais". Tal perspectiva enfatizava o caráter instrumental, tendo como objeto de estudo as mensagens, a transmissão de informações, os códigos, o emissor, o receptor e os canais.

O cenário apresentado prova, assim, que o campo da comunicação latino-americana durante o século XX foi baseado em teorias, métodos e pesquisas gerados no hemisfério Norte e a partir de um modelo neoliberal; vale ressaltar algumas exceções em que o pensamento comunicacional latino-americano foi gerado em um espaço de debate, no qual dicotomia, emancipação ou dependência dependiam do grau de desenvolvimento de cada país, conforme mencionado na seção anterior.

Boaventura de Sousa Santos (1998) sugere que o urgente pensamento transmoderno e a comunicação transmoderna, que seria seu correlato, parecem não fazer parte de um futuro próximo da produção de conhecimento na região. Dito isso, Flores Prieto, Pozo e Crawford complementam:

0 desmonte das narrativas ocidentais sobre nossa história, realizado pelo grupo Modernidad/Colonialidad, bem como o trabalho de democratização da comunicação que, desde a década de 1960, figuras como Luis Ramiro Beltrán empreenderam, por meio da censura ao desenvolvimentismo e da nossa dependência epistemológica e cultural, junto com a proposta de um modelo participativo de comunicação (Barraquero, 2014), constituem um corpus inestimável para repensar o papel da comunicação na América Latina no contexto da globalização e das tecnologias de informação. (Flores Prieto; Pozo; Crawford, 2018, p.97)

O giro decolonial e a "desobediência epistêmica", segundo Mignolo (2007, p.45) são posições que colaboraram para "reconstruir, dentro do imaginário social, como cidadãos não marginais do Ocidente, uma herança cultural múltipla e com capacidade de consolidar um ponto de enunciação a partir do qual deixamos de ser o 'outro' para sermos nós mesmos" (Flores Prieto; Pozo; Crawford, 2018, p.98). Assim, o giro decolonial revela um caminho potencial para uma mudança de postura, seja de comunicadores e acadêmicos, seja de organizações, para se tornar o discurso central de uma agenda que propõe uma comunicação democrática, participativa e cidadã.

Com base no exposto, as sociedades latino-americanas têm sido pressionadas, por um lado, pela globalização para aumentar e garantir seu lugar no mercado e pelo poder que exercem ao ditar valores às sociedades e, por outro, por uma agenda crítica, que expressa o esgotamento do pensamento moderno e a resistência das práticas que exercem uma forma de poder. 
Refletir sobre o cenário atual do século XXI é, portanto, observar que "a comunicação organizacional tem sido cada vez mais reconhecida como um processo fundamental para a existência das organizações e como um espaço de produção e reprodução organizacional" (Deetz, 2010, p.93).

Observa-se que os estudos culturais assumiram um papel importante ao fornecerem elementos teóricos para entender as organizações e como elas alcançam uma visão comum, a partir das experiências compartilhadas de um determinado grupo, que ensina como lidar com problemas de adaptação, internos e externos (Ferrari, 2011). Além disso, os estudos culturais permitiram compreender a organização como um sistema de significados compartilhados, capaz de aprender, mudar e evoluir ao longo do tempo, a partir da interação entre seus membros e com o meio ambiente.

As pesquisas e estudos realizados desde então têm ampliado a noção de comunicação, especialmente no contexto das organizações, compreendendo-a a partir de sua complexidade e da ideia de interação, que incorpora alguns elementos do paradigma informacional. Neste século, as abordagens buscam abarcar a complexidade da sociedade e do ser humano e a construção de significados, sem perder de vista, contudo, sua função informativa, e sem reduzi-la a esta ocupação.

\section{A GESTÃO DA DIVERSIDADE NO CONTEXTO DAS ORGANIZAÇÕES LATINO-AMERICANAS}

Como comentado no início do texto, o grande desafio para as organizações da região é repensar os referenciais globais e interpretar a gestão organizacional como prática social local, analisando consequências que as matrizes hegemônicas causaram para o desenvolvimento dos países da região e, em seguida, incorporar políticas locais (Ibarra-Colado, 2006).

Para iniciar esta seção é importante conceituar o termo diversidade. Diversidade é conviver, respeitar e aceitar o diferente (Ferrari; Cabral, 2020). A gestão da diversidade, segundo Cox (1994, p.11), é um conjunto de ações que tem como foco "planejar e executar sistemas e práticas de gestão de pessoas de modo a maximizar as vantagens e minimizar as potenciais desvantagens da diversidade". Segundo o autor, pelo menos três grandes objetivos organizacionais podem ser alcançados por meio dessas políticas: responsabilidade social, obrigações legais e melhoras dos resultados.

0 complexo contexto contemporâneo latino-americano tem se caracterizado pela disputa de poder por vários atores como alta administração, trabalhadores, grupos minorizados, Estado, meios de comunicação, ONG, entre outros. Como resultado, muitas vezes sob o pretexto do discurso em favor da diversidade, algumas situações de injustiça e desigualdade podem ser ocultadas de modo a conceber todos os indivíduos de uma organização como iguais, embora sejam diferentes e estejam em situações e posições distintas no que se refere a questões como acesso a oportunidades, poder econômico, contexto social, identidade de gênero, étnico-racial, entre outras (Ferrari; Cabral, 2020).

Alves e Galeão-Silva (2004) criticam as práticas de empresas latino-americanas que têm se baseado na ideia funcionalista de que a gestão de diversidade é apenas considerada uma vantagem competitiva. Ou seja, o caminho, segundo Coelho Jr. (2015, p.93), "seria que elas (empresas) se conscientizassem de que a diversidade cultural é um capital simbólico e comunicacional".

Especificamente no contexto brasileiro, Coelho Jr. (2015) defende que a questão da diversidade não deve ser interpretada nem como vantagem competitiva (Fleury, 2000), nem como ideologia (Alves; Galeão-Silva, 2004). 0 autor propõe uma terceira via analítica, a partir da ideia de "tradução", e afirma que "aquilo que se apresenta inicialmente como um movimento político-as lutas por reconhecimento de identidades específicas -, ao ser traduzido pelas empresas, sofre um deslocamento de sentido que o empobrece, reduzindo-o a uma metodologia administrativa" (Coelho Jr., 2015, p.10). 
Os resultados apresentados por Ogliastri (2000) no âmbito do projeto Globe e por Tanure (2005), apontaram algumas características culturais que ainda permeiam as sociedades latino-americanas e ocultam a urgência do tratamento da diversidade. Traços que ainda perduram em muitas organizações latino-americanas, como paternalismo, autoritarismo, machismo, preconceitos raciais e étnicos, impedem que a gestão organizacional seja mais humana e inclusiva. Consequentemente, o processo de comunicação é, por fim, limitado, ficando muitas vezes dependente das estratégias estabelecidas pela alta direção.

Quando os ventos são contrários, a afirmação de Saraiva e Irigaray (2009, p.339) mostra que "possivelmente por conta de um ideal de tecnicismo, as organizações adotam uma visão de homogeneidade no seu cotidiano: lidam com seus empregados como se suas diferenças pudessem desaparecer sob a formalidade das posições hierárquicas". Ou seja, persiste a mentalidade de que a homogeneidade de pensamento dos trabalhadores continua sendo um "mantra" organizacional, cujos discursos pretendem construir uma realidade que não existe na organização.

Quando os ventos sopram a favor, observa-se que, na região, já existem organizações que estão em processo de transição da gestão autoritária para a gestão participativa, como resultado de imposições do contexto externo, da crescente atividade de grupos ativistas e do contexto internacional (Ferrari, 2011). Em muitas situações, a comunicação organizacional passa a atuar como uma função mais estratégica e menos instrumental, muito embora, sob a pressão do sistema capitalista, as organizações busquem maximizar a eficácia e a eficiência de seu desempenho para enfrentar a concorrência, e a comunicação torna-se útil para o mercado, sem assumir sua função de produção de sentido compartilhado para os trabalhadores.

Nossa conclusão está em consonância com o que defende Jesús Martín-Barbero (2010) ao se referir ao contexto latinoamericano. Para o autor, a diversidade cultural deve ser o espaço não só de resistência, mas também de interação e de transformação da globalização.

\section{CONSIDERAÇÕES FINAIS}

0 presente artigo buscou mostrar as intersecções entre o contexto político, econômico e social, as culturas nacional e organizacional, o pensamento comunicacional e a comunicação organizacional na América Latina, enfatizando a perspectiva da gestão da diversidade e levando em consideração o fato de que o conhecimento importado sempre predominou na região. Procurou-se enfatizar, também, que as culturas nacionais e organizacionais são vitais para a compreensão dos processos de comunicação nas/das organizações na América Latina.

No entanto, pouco sabemos sobre as organizações latino-americanas, e menos ainda sobre suas culturas e modelos de comunicação, uma vez que são escassos os estudos e pesquisas sobre a influência da comunicação nas organizações latinoamericanas. 0 fio condutor aqui apresentado consiste apenas na "ponta do iceberg". Assim, é necessário desenvolver estudos para conhecer as culturas nacionais e compreender como elas influenciam a cultura organizacional e, por conseguinte, como se formam os espaços de comunicação e qual sua importância na produção de sentidos.

Para finalizar, é importante avançar em algumas conclusões que podem seguir orientando a análise do processo de comunicação organizacional na região: 1) a visão de mundo das sociedades latino-americanas continua a ser conservadora, o que influi na gestão das organizações; 2) características como paternalismo, conservadorismo, centralização do poder, impunidade, machismo e desconfiança continuam presentes nas culturas nacionais, influindo nas culturas organizacionais; 3) o espaço para o processo de comunicação está, muitas vezes, definido pela alta administração, de quem depende o grau de conhecimento da área; 4) as organizações se referem ao diálogo como parte do discurso, porém, esse diálogo parece ser pouco praticado, principalmente pelos formatos cada vez mais sofisticados de explorar e controlar os sujeitos, na maioria das vezes em benefício 
de interesses corporativos; 5) é baixa a preocupação das organizações em dar voz aos trabalhadores como sujeitos políticos no processo de comunicação no ambiente de trabalho; 6) Ainda que de maneira incipiente, as organizações começam a mudar seus processos de gestão, passando a preocupar-se com assuntos como sustentabilidade, diversidade e governo corporativo, dimensões que influem diretamente nos negócios da empresa e no comportamento dos trabalhadores, principalmente quando a comunicação organizacional se transforma em processo de produção de sentidos; 7) muitas organizações continuam a valorizar os resultados da comunicação unicamente pela perspectiva de custo-benefício, quando deveriam analisar os resultados intangíveis que melhoram a vida dos trabalhadores.

As palavras de Flores Prieto, Pozo e Crawford (2018, p.104) sintetizam o objetivo do artigo: "depois de 500 anos de desigualdades e frustrações, assomam tentativas para recuperar uma identidade que não seja marginal e não só resistências. Uma identidade afirmativa que esteja apoiada em saberes tradicionais, mas também nas inéditas solidariedades que produzem novos grupos sociais no mutável universo contemporâneo".

\section{REFERÊNCIAS}

AIDAR, Marcelo Marinho; ALVES, Mario Aquino. Comunicação de massa nas organizações brasileiras: explorando o uso da história em quadrinhos, literatura de cordel e outros recursos populares de linguagem nas empresas brasileiras. In: PRESTES MOTTA, Fernando; CALDAS, Miguel Pinto (org.). Cultura organizacional e cultura brasileira. São Paulo: Atlas, 1997. p.203-220.

ALVES, Mario Aquino; GALEÃO-SILVA, Luís Guilherme. A crítica da gestão da diversidade nas organizações. RAE-Revista de Administração de Empresas, São Paulo, v.44, n.3, p.20-29, 2004. doi: https://doi.org/10.1590/S0034-75902004000300003.

COELHO JR., Pedro Jaime de. Diversidade nas organizações: entre a riqueza cultural e a disputa política. In: MOURA, Cláudio Peixoto; FERRARI, Maria Aparecida (org.). Comunicação, interculturalidade e organizações: faces e dimensões da contemporaneidade. Porto Alegre: EDIPUCRS, 2015. p.67-95.

COX, Taylor. Cultural diversity in organizations: theory, research, and practice. San Francisco: Berrett-Koehler, 1994.

DÁVILA, Anabella; MARTíNEZ, Nora. (coord.) Cultura en organizaciones latinas. Ciudad de México: Siglo Veintiuno, 1999.

DEETZ, Stanley. Comunicação organizacional: fundamentos e desafios. In: MARCHIORI, Marlene (org.). Comunicação e organização: reflexões, processos e práticas. São Caetano do Sul: Difusão, 2010. p.83-101.

FERRARI, Maria Aparecida. Os cenários turbulentos como oportunidade de mudança e de realinhamento de estratégias. In:GRUNIG, James; FERRARI, Maria Aparecida; FRANÇA, Fábio. (org.). Relações públicas: teoria, contexto e relacionamentos. São Caetano do Sul: Difusão, 2011. p.137-166.

FERRARI, Maria Aparecida; CABRAL, Raquel. Comunicação intercultural e interseccionalidade: breve reflexão sobre as perspectivas e os desafios da diversidade nas organizações. In: FARIAS, Luiz Alberto; LEMOS, Else; REBECHI, Cláudia (org.). Opinião pública, comunicação e organizações: convergências e perspectivas contemporâneas. São Paulo: Abrapcorp, 2020. p.290-314.

FLEURY, Maria Tereza Leme. Gerenciando a diversidade cultural: experiências de empresas brasileiras. RAE: Revista de Administração de Empresas, São Paulo, v.40, n.3, p.18-25, 2000. 
FLORES PRIETO, Pamela; POZO, Kelly; CRAWFORD, Livingston. La comunicación en América Latina: un debate pendiente más allá de las resistencias. Signo y Pensamiento, Bogotá, v.37, n.72, p.95-105, 2018. doi: https://doi.org/10.11144/Javeriana. syp37-72.camd.

FOUCAULT, Michel. Vigilar y castigar. Nacimiento de la Prisión. Ciudad de México: Siglo XXI, 1980.

FREITAS, Maria Ester de. Cultura organizacional: formação, tipologias e impactos. São Paulo: Makron McGraw-Hill, 1991.

GAULEJAC, Vincent de. Gestão como doença social: ideologia, poder gerencialista e fragmentação social. São Paulo: Ideias \& Letras, 2007.

GONZÁLES-MIRANDA, Diego René. Los estudios organizacionales en Latinoamérica: ivuelta al terreno áspero! RAE-Revista de Administração de Empresas, São Paulo, v.60, n.2, p.104-119, 2020. doi: https://doi.org/10.1590/S0034-759020200204.

HERRERA, Karina. Luis Ramiro Beltrán: el pensamiento comunicacional propio y emancipador en Latinoamérica rebelde. Revista Internacional de Comunicación y Desarrollo, Santiago de Compostela, n.3, p.125-134, 2015. Disponível em: https://dialnet.unirioja.es/descarga/articulo/5315867.pdf. Acesso em: 13out. 2021.

HOFSTEDE, Geert. Culture's consequences: comparing values, behaviors, institutions, and organizations across nations. Thousand Oaks: Sage, 2001.

IBARRA-COLADO, Eduardo. Is there any future for critical management studies in Latin America? Moving from epistemic coloniality to 'trans-discipline'. Organization, Thousand Oaks, v.15, n.6, p.932-935, 2008. doi: https://doi.org/10.1177/1350508408095822.

IBARRA-COLADO, Eduardo. Organization studies and epistemic coloniality in Latin America: thinking otherness from the margins. Organization, Thousand Oaks, v.13, n.4, p.463-488, 2006. doi: https://doi.org/10.1177/1350508406065851.

MARTÍN-BARBERO, Jesús. De los medios a las mediaciones. Comunicación, cultura y hegemonía. Barcelona: Anthropos, 2010.

MARTÍN-BARBERO, Jesús. Projetos de modernidade na América Latina. In: DOMINGUES, José Maurício; MANEIRO, María (org.). América Latina hoje: conceitos e interpretações. Rio de Janeiro: Civilização Brasileira, 2006. p.19-51.

MIGNOLO, Walter. Delinking: the rhetoric of modernity, the logic of coloniality and the grammar of de-coloniality. Cultural Studies, London, v.21, n.2-3, p.449-514, 2007. doi: https://doi.org/10.1080/09502380601162647.

MIGNOLO, Walter. The darker side of Western modernity. Global futures, decolonial options. Durham: Duke University Press, 2011.

MIGNOLO, Walter. The idea of Latin America. London: Blackwell, 2008.

OGLIASTRI, Enrique. El estilo negociador de los latinoamericanos. Una investigación cualitativa. Revista Latinoamericana de Administración, Bogotá, n.25, p.43-58, 2000.

OLIVEIRA, Ivone de Lourdes; PAULA, Maria Aparecida de. O que é comunicação estratégica nas organizações? São Paulo: Paulus, 2007. 
PETTIGREW, Andrew. On studying organizational cultures. ASQ, Thousand Oaks, v.24, n.4, 1979.

PRESTES MOTTA, Fernando; CALDAS, Miguel Pinto (org.). Cultura organizacional e cultura brasileira. São Paulo: Atlas, 1997.

QUIJANO, Aníbal. Colonialidad del poder, eurocentrismo y América Latina. In: LANDER, Edgardo (org.). La colonialidad del saber. eurocentrismo y ciencias sociales. Perspectivas latinoamericanas. Buenos Aires: CLACSO, 2000. p.117-142.

RIZO, Marta. La comunicación en, desde y para la cultura. Apuntes para un balance de los Estudios Culturales (en Comunicación) en América Latina: trayectoria, temas y críticas. In: PAULINO, Fernando Oliveira; KAPLÚN, Gabriel; MARIÑO, Miguel Vicente; CUSTODIO, Leonardo. Tradiciones de investigación en diálogo - estudios sobre comunicación en América Latina y Europa. Ramada: Media XXI, 2020. p.161-188.

SARAIVA, Luiz Alex Silva; IRIGARAY, Hélio Arthur dos Reis. Políticas de diversidade nas organizações: uma questão de discurso? RAE-Revista de Administração Empresas, São Paulo, v.49, n.3, p.337-348, 2009.

SENNETT, Richard. La corrosión del carácter. Las consecuencias personales del trabajo en el nuevo capitalismo. Barcelona: Anagrama, 2000.

SOUSA SANTOS, Boaventura. De la mano de Alicia. Lo social y lo político en la postmodernidad. Bogotá: Siglo del Hombre; Ediciones Uniandes, 1998.

SZLECHTER, Diego; SOLARTE PAZOS, Leonardo; TEIXEIRA, Juliana Cristina; FEREGRINO, Jorge; ISLA MADARIAGA, Pablo; ALCADIPANI, Rafael. Estudios organizacionales en América Latina: hacia una agenda de investigación. RAE-Revista de Administração de Empresas, São Paulo, v.60, n.2, p.84-92, 2020. doi: https://doi.org/10.1590/s0034-759020200202.

TANURE, Betania. Gestão à Brasileira. 2.ed. São Paulo, Brasil: Atlas, 2005.

Artigo recebido em 18.07.2021 e aprovado em 27.09.2021. 